\title{
МЛЭ буферных слоев GaP на Si для формирования \\ квантово-размерных гетероструктур
}

М.О. Петрушков, М.А. Путято, Б.Р. Семягин, Е.А. Емельянов, Д.С. Абрамкин, А.В. Васев, Д.Б. Богомолов, В.В. Преображенский

Институт физики полупроводников им. А.В. Ржанова СО РАН, Новосибирск, 630090, пр. Академика Лаврентьева, 13, тел:+7 (383) 333-19-67, эл.почта: maikdi@isp.nsc.ru

DOI 10.34077/RCSP2019-113

Интеграция соединений $\mathrm{A}^{\mathrm{III}} \mathrm{B}^{\mathrm{V}}$ в кремниевую технологию требует получения совершенных буферных слоев с малой толщиной (до 1 мкм). Фосфид галлия является перспективным материалом для решения этой задачи. Во-первых, из-за малого несоответствия параметров решетки $\mathrm{GaP}$ c $\mathrm{Si}$ (около $0.3 \%$ ). Во-вторых, в квантово-размерных гетероструктурах из узкозонных материалов в широкозонной матрице $\mathrm{GaP}$ наблюдается сильная локализация носителей заряда, что обеспечивает высокую температурную стабильность приборов на их основе. Несмотря на хорошее согласование параметров решеток, выращивание $\mathrm{GaP}$ на $\mathrm{Si}$ с требуемыми характеристиками является нетривиальной задачей. Для ее решения необходимо обеспечить формирование совершенного сплошного слоя $\mathrm{GaP}$ на $\mathrm{Si}$ на начальных этапах роста.

В настоящее время наиболее успешным способом достижения указанной цели является использование методики эпитаксии с повышенной миграцией (ЭПМ) (migration-enhanced epitaxy MEЕ). ЭПМ представляет собой поочередное взаимодействие поверхности подложки с потоком молекул III и V групп. Временное отсутствие потока фосфора позволяет адсорбированным на поверхности атомам $\mathrm{Ga}$ более длительное время мигрировать по поверхности полупроводника без образования химической связи. Это позволяет формировать на поверхности $\mathrm{Si}$ сплошные пленки $\mathrm{GaP}$ без перехода в островковый режим роста.

На начальных этапах роста толщина таких слоев должна составлять не менее 100 нм. Это обеспечивает сохранение сплошности пленки и подавление развития рельефа поверхности при дальнейшем росте в обычном режиме МЛЭ. Получение эпитаксиальных слоев такой толщины методом ЭПМ требует значительных временных затрат.

$\mathrm{B}$ данной работе предложен модифицированный метод ЭПМ для роста $\mathrm{GaP}$ на $\mathrm{Si}$. Главное отличие заключается в том, что на поверхность подложки поток молекул V группы подается постоянно, при этом отношение потоков V/III устанавливается меньше 1. Таким образом, обеспечиваются условия обогащения поверхности атомами третьей группы, что также как и в методе ЭПМ, способствует увеличению длины диффузии атомов Ga по поверхности. Чтобы избежать образования капель Ga, необходимо периодически закрывать заслонку источника галлия и выдерживать поверхность в потоке молекул фосфора, пока весь избыточный $\mathrm{Ga}$ не встроится в кристалл. Таким образом, время роста слоя оказывается в несколько раз меньше, чем при ЭПМ.

$\mathrm{C}$ использованием предложенной методики были выращены буферные слои $\mathrm{GaP}$ на $\mathrm{Si}$ толщиной 500 нм и гетероструктуры с квантовыми ямами (КЯ) GaAs в матрице $\mathrm{GaP}$ на аналогичных буферных слоях. Для сравнения были выращены такие же структуры на подложках $\mathrm{GaP}$. Образцы исследованы методом низкотемпературной фотолюминесценции (ФЛ).

На рисунке 1 (а) представлены спектры ФЛ слоев GaP, выращенных на подожках $\mathrm{GaP}$ и $\mathrm{Si}$ (обозначены как «1» и «2», соответственно). В обоих спектрах доминируют полосы донорно-
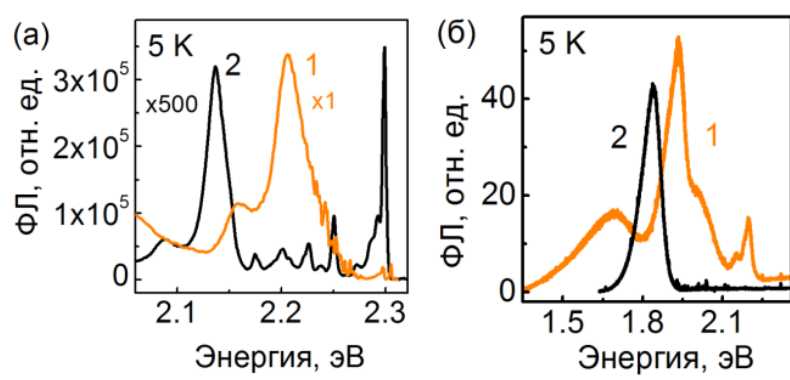

акцепторной рекомбинации. Интегральная интенсивность ФЛ в слое $\mathrm{GaP} / \mathrm{Si}$ почти в 500 раз ниже, чем для слоя $\mathrm{GaP} / \mathrm{GaP}$, что свидетельствует о высокой концентрации центров безызлучательной рекомбинации в структуре $\mathrm{GaP} / \mathrm{Si}$.

На рисунке 1 (б) представлены спектры ФЛ гетероструктур с КЯ $\mathrm{GaAs} / \mathrm{GaP}$, выращенными на подложке $\mathrm{GaP}$ и буферных слоях $\mathrm{GaP}$ на $\mathrm{Si}$. Несмотря на высокую концентрацию центров безызлучательной рекомбинации в слое $\mathrm{GaP}$ на $\mathrm{Si}$, интенсивность ФЛ КЯ сравнима с интенсивностью ФЛ аналогичной КЯ, выращенной на подложке $\mathrm{GaP}$, что обусловлено сильной пространственной локализацией носителей заряда в КЯ. Структуры характеризуются высокой эффективностью и температурной стабильностью ФЛ, сравнимой с гетероструктурами, выращенными на согласованных $\mathrm{GaP}$ подложках.

Работа выполнена в рамках ГЗ 0306-2016-0011, 0306-2018-0011 и при поддержке гранта РФФИ 1832-00125. 